\title{
Use of Complementary and Alternative Medicine in Patients with Cancer and their Relationship with Health Behaviours: A Cross-Sectional Study
}

\author{
Aneta B. Jędrzejewska ${ }^{1}$, Zdzisława Szadowska-Szlachetka²and Barbara Ślusarska ${ }^{3}{ }^{, *}$ \\ 1 Department of Family Medicine and Community Nursing, Faculty of Health Sciences, Medical University \\ of Lublin, Poland; jedrzejewska.ab@gmail.com \\ 2 Chair of Oncology and Environmental Health, Faculty of Health Sciences, Medical University of Lublin, \\ Poland; zdzislawaszadowskaszlachetka@umlub.pl \\ 3 Department of Family Medicine and Community Nursing, Faculty of Health Sciences, Medical University \\ of Lublin, Poland; barbaraslusarska@umlub.pl \\ * Author to whom correspondence should be addressed.
}

\begin{abstract}
An increasing number of persons with cancer decide to choose complementary and alternative medicine. The purpose of the paper was to check the status of the use of complementary and alternative medicine methods in oncological patients and to compare health behaviours of patients using Complementary and Alternative Medicine (CAM) with those using neither of these methods. The studies were conducted from August till January 2020 in the Oncology Center in the south-eastern Poland. A cross-sectional study was conducted in a group of 208 oncological patients. The authors' own questionnaire and the standardized Health Behaviour Inventory were used. Most of the patients $(85,09 \%)$ declared that they used complementary and alternative medicine methods. The most common methods chosen by the respondents included vitamin $\mathrm{C}$, green tea and prayer. The vast majority of the respondents did not inform their oncologist about the use of CAM. $45,19 \%$ of the respondents had a high rate of health behaviours. It was observed that there was no communication related to the use of CAM among the patients and healthcare staff. Patients using CAM demonstrated more positive health behaviours than those who were not using these methods.
\end{abstract}

Keywords: cancer; alternative medicine; complementary medicine; health behaviours

\section{Introduction}

The search for methods of treatment other than conventional ones might be caused by a fear of symptoms resulting from the disease progress and systematic anticancer therapy, high mortality as well as great determination of patients and their families who strive for remission of the disease [1]. An increasing number of persons with cancer decide to choose complementary and alternative medicine as an active way of coping with physical, psychological and spiritual consequences associated with the disease [2-4].

Complementary and Alternative Medicine (CAM) includes medical products and practices that do not constitute a part of standard healthcare. Some of the therapies belonging to the complementary and alternative medicine were studied thoroughly and their safety and effectiveness were confirmed. Other therapies were found to be ineffective and potentially harmful. [5] Information on numerous therapies carried out as part of alternative and complementary medicine is limited and the studies take a lot of time [6].

In a large cohort study involving 1901815 patients, the use of CAM differentiates the group according to several factors and it was associated with a refusal to use conventional cancer treatment and with a twice higher risk of death, compared to the patients who did not use CAM [7]. 
In Poland, there is no reliable data on the use of CAM by oncological patients, and since 2017, there has been an educational website launched by Polska Liga Walki z Rakiem (Polish League to Fight Cancer) devoted to alternative and complementary methods used by patients suffering from cancer [8].

Active participation of patients in the treatment of cancer should be associated with a high level of patient's knowledge about the disease and behaviours supporting the recovery, cooperation with the therapeutic team and also alternative methods of treatment. Health behaviours, as a factor strongly related to health or disease, could be a health determinant that helps in recovery, but also with predominance of anti-health activities, they might be the cause of cancer $[9,10]$.

\section{The objective of the paper}

The objective of the paper was to check the status of the use of complementary and alternative medicine methods in oncological patients and to compare the health behaviours of the patients who use alternative medicine with those who use neither of these methods.

\section{Materials and methods}

\subsection{Design and Sample}

The cross-sectional studies using the diagnostic survey method wereconducted from August till January 2020 in the Oncology Center in the south-eastern Poland. Moreover, a survey was placed on Internet forums and social networking sites related to cancer and unconventional treatment. A total of 280 questionnaires were distributed, 189 of which were given back (67,5\% response). Due to the fact that some questionnaires were not fully completed, 29 persons were excluded from the study. Also, 48 responses were received from the online form. Finally, 208 patients took part in the study.

\subsection{Measures}

In order to measure the use of complementary and alternative medicine, the authors' own questionnaire was used, containing 19 closed and open questions, single and multiple choice. The open-ended responses were optional and they allowed the participants to report any other CAM practices that were not included in the survey. The questions concerned sociodemographic data, type of cancer, time passed after the diagnosis of the disease, type of past and present treatment, knowledge and use of selected methods of complementary medicine, reasons why patients decided to use or not to use complementary medicine, benefits perceived while using CAM, sources of knowledge and consultations with a doctor on using complementary and alternative medicine. In order to measure health behaviours, a standardized tool -Zygfryd Juczyński'sthe Health Behaviour Inventory, HBI (Inwentarz Zachowań Zdrowotnych, IZZ) was used as a self-report tool that consists of 25 statements regarding different health behaviours. It makes it possible to assess the intensity of health-promoting behaviours (HP), as well as to assess the intensity indicator in four categories of health-related behaviours: proper eating habits (PH1), preventive behaviours (PB), positive mental attitude (PA2) and health practices (HP)

The value of the overall HBI indicator ranges from 24 to 120 points. The higher the result, the higher intensity of the declared pro-health behaviours. After conversion into standardized units, this indicator is subject to interpretation in the sten scores [11].

\subsection{Statistical Analysis}

The results obtained were coded in the Microsoft Office 2010 Excel database prepared for the purpose of the study and their statistical analysis was conducted using Statistica 9.1. The values of the measurable parameters analyzed were presented using the mean value and standard deviation, and for the unmeasurable - using numbers and percentages. In order to examine the differences in measurable parameters between the two groups, the Shapiro-Wilk, Student's t-test and Mann - 
Whitney's U test were applied. The level of significance of $p<0,05$ was adopted, indicating the existence of statistically significant differences and dependencies.

\subsection{Statement of Ethics}

This research was carried out in accordance with the principles of the Helsinki Declaration and approved by the Bioethics Committee of the Medical University (N. KE-0254/128/2018). The survey was conducted after obtaining the consent of the Director of the healthcare centre. Participation in the study was voluntary and anonymous. Each patient was informed about the purpose of the study and how to complete the questionnaire, then the consent to take part in the study was obtained.

\section{Results}

\subsection{Characteristics of the patients participating in the survey}

$53,85 \%$ of 208 surveyed patients were male. The largest age group (33,17\%) were patients in the 60-69 age group. Most of the respondents (62,98\%) declared that they lived in a city/town. The most common type of cancer that the respondents were suffering from was colorectal cancer $(19,71 \%)$ and lung cancer $(12,02 \%)$. More than half of the surveyed group $(53,85 \%)$ were persons with less than a year after the disease had been diagnosed (Table 1.)

Table 1. Characteristics of the group participating in the survey.

\begin{tabular}{|c|c|c|c|}
\hline Variable & & $\mathbf{n}$ & $\%$ \\
\hline Age & $18-39$ & 21 & $10,1 \%$ \\
\hline \multirow[t]{4}{*}{ [years] } & $40-49$ & 39 & $18,75 \%$ \\
\hline & $50-59$ & 51 & $24,52 \%$ \\
\hline & $60-69$ & 69 & $33,17 \%$ \\
\hline & $70-80$ & 28 & $13,46 \%$ \\
\hline \multirow[t]{2}{*}{ Sex } & Female & 96 & $45,16 \%$ \\
\hline & Male & 112 & $53,85 \%$ \\
\hline \multirow[t]{4}{*}{ Education } & Elementary & 15 & $7,21 \%$ \\
\hline & Vocational & 58 & $27,88 \%$ \\
\hline & Secondary & 70 & $33,65 \%$ \\
\hline & Higher & 65 & $31,25 \%$ \\
\hline \multirow[t]{4}{*}{ Professional status } & Employed & 81 & $38,94 \%$ \\
\hline & Unemployed & 12 & $5,77 \%$ \\
\hline & Retired with a disability pension & 37 & $17,79 \%$ \\
\hline & Retired & 78 & $37,5 \%$ \\
\hline \multirow[t]{2}{*}{ Place of living } & Village & 77 & $37,02 \%$ \\
\hline & City/town & 131 & $62,98 \%$ \\
\hline \multirow[t]{3}{*}{ Marital status } & Married & 165 & $79,33 \%$ \\
\hline & Single & 26 & $12,5 \%$ \\
\hline & Widowed & 17 & $8,17 \%$ \\
\hline \multirow[t]{3}{*}{ Type of cancer } & Colorectal & 41 & $19,71 \%$ \\
\hline & Lung & 25 & $12,02 \%$ \\
\hline & Breast & 20 & $9,62 \%$ \\
\hline
\end{tabular}




\begin{tabular}{clll} 
& Gynecological & 19 & $9,13 \%$ \\
& Prostate & 18 & $8,65 \%$ \\
& Genitourinary & 14 & $6,73 \%$ \\
& Digestive system & 14 & $6,73 \%$ \\
Oral cavity & 13 & $6,25 \%$ \\
& ENT & 12 & $5,77 \%$ \\
& Brain & 10 & $4,81 \%$ \\
& Lymphoma & 10 & $4,81 \%$ \\
& Other & 12 & $5,77 \%$ \\
Time after the disease started & $0-1$ year & 112 & $53,85 \%$ \\
& $1-2$ years & 45 & $21,63 \%$ \\
& More than 3 years & 51 & $24,52 \%$ \\
\hline
\end{tabular}

\subsection{The use of complementary and alternative medicine}

More than half of the respondents knew the definition of complementary medicine $(46,15 \%)$, $28,37 \%$ confused complementary medicine with alternative medicine, whereas $25,48 \%$ of the respondents believed that complementary medicine involved additional medicines prescribed by a doctor.

The use complementary and alternative medicine was declared by 177 out of 208 patients $(85,09 \%)$, of whom $10,58 \%$ of the respondents declared using alternative medicine exclusively. Among the respondents using CAM, the most popular were Vitamin C, prayer and green tea.

Table 2. Methods and frequency of the use of CAM by the respondents.

\begin{tabular}{lcc}
\hline CAM methods & $\mathbf{n}$ & $\mathbf{\%}$ \\
\hline Natural products & 117 & \\
Vitamin C & 93 & $66,10 \%$ \\
Green tea & 89 & $52,54 \%$ \\
Vitamin D & 86 & $50,28 \%$ \\
Curcuma & 81 & $48,59 \%$ \\
Multivitamins & 80 & $45,76 \%$ \\
Herbs & 76 & $42,94 \%$ \\
Ginger & 74 & $41,81 \%$ \\
Probiotics & 64 & $36,16 \%$ \\
Minerals & 50 & $28,25 \%$ \\
B17 & 33 & $18,64 \%$ \\
Marijuana & & \\
& & \\
Body and mind practices & 128 & $72,32 \%$ \\
Prayer & 52 & $29,38 \%$ \\
Special diet & 37 & $20,90 \%$ \\
Relaxation & 32 & $18,08 \%$ \\
Massage & 22 & $12,43 \%$ \\
Meditation & 12 & $6,78 \%$ \\
Yoga & 10 & $5,65 \%$ \\
Aromatherapy & & \\
Other & & \\
Homeopathy & 14 & $7,91 \%$ \\
Traditional healers & 11 & $6,21 \%$ \\
Traditional Chinese Medicine & 10 & $5,65 \%$ \\
\end{tabular}




\begin{tabular}{lcc} 
Frequency of use & n & \% \\
\hline Every day & 91 & $51,48 \%$ \\
A few times per week & 51 & $28,81 \%$ \\
Less frequently & 28 & $19,77 \%$ \\
\hline
\end{tabular}

The most common reasons that encouraged the patients to use CAM were increased chances of recovery $(67,80 \%)$, an improvement in general condition of the body and immunity $(66,67 \%)$ and a reduction of treatment side effects $(33,33 \%)$. The factors that discouraged them from using CAM included lack of knowledge about the methods $(39,9 \%)$ and a fear of unknown methods $(19,23 \%)$. Over half of the patients $(51,41 \%)$ declared that they used alternative medicine methods every day and $28,81 \%$ a few times per week. According to the subjective assessment of almost half of the respondents $(46,33 \%)$, the use of CAM was very helpful for them, for $42,37 \%$ - slightly helpful. The patients declared that the methods of alternative medicine were helpful in boosting the immune system $(54,2 \%)$, helpful in fighting cancer $(38,42 \%)$ and improving the quality of life $(34,46 \%)$. For almost half $(46,15 \%)$ of the respondents, the source of information on CAM was the Internet, then family $(37,02 \%)$ and friends (35,1\%). As many as 71,19\% of the patients did not inform their oncologist about the use of complementary and alternative medicine. 32 out of 51 persons $(62,75 \%)$ who informed their doctor about using CAM gained his/her approval.

CAM was used more often by the patients with more than 2 years after the diagnosis and by male persons with higher education, living in a village (Table 3)

Table 3. Factors determining an increase in the frequency of using CAM.

\begin{tabular}{|c|c|c|c|}
\hline \multirow{3}{*}{$\begin{array}{l}\text { Variable analyzed } \\
\text { Time after the disease diagnosis }\end{array}$} & \multicolumn{2}{|c|}{$\begin{array}{l}\text { Use of alternative and } \\
\text { complementary medicine } \\
\text { method }\end{array}$} & \multirow[t]{3}{*}{$\begin{array}{c}\mathrm{Chi}^{2} \\
\mathrm{p}\end{array}$} \\
\hline & using & not using & \\
\hline & & & \\
\hline \multirow{2}{*}{ 0-1 year } & 89 & 23 & \multirow{6}{*}{$\begin{array}{c}\mathrm{Chi}^{2}=7,739 \\
\mathrm{p}=0,021\end{array}$} \\
\hline & $79,46 \%$ & $20,54 \%$ & \\
\hline \multirow{2}{*}{ 1-2 years } & 39 & 6 & \\
\hline & $86,67 \%$ & $13,33 \%$ & \\
\hline \multirow{2}{*}{ Over 2 years } & 49 & 2 & \\
\hline & $96,08 \%$ & $3,92 \%$ & \\
\hline \multicolumn{4}{|l|}{ Sex } \\
\hline \multirow{2}{*}{ Males } & 89 & 7 & \multirow{4}{*}{$\begin{array}{c}\mathrm{Chi}^{2}=8,146 \\
\mathrm{p}=0,004\end{array}$} \\
\hline & $92,71 \%$ & $7,29 \%$ & \\
\hline \multirow{2}{*}{ Females } & 88 & 24 & \\
\hline & $78,57 \%$ & $21,47 \%$ & \\
\hline \multicolumn{4}{|l|}{ Education } \\
\hline \multirow{2}{*}{$\begin{array}{l}\text { Primary/ } \\
\text { vocational }\end{array}$} & 56 & 17 & \multirow{6}{*}{$\begin{array}{c}\mathrm{Chi}^{2}=7,991 \\
\mathrm{p}=0,018\end{array}$} \\
\hline & $76,71 \%$ & $23,29 \%$ & \\
\hline \multirow{2}{*}{ Secondary } & 60 & 10 & \\
\hline & $85,71 \%$ & $14,29 \%$ & \\
\hline \multirow{2}{*}{ Higher } & 61 & 4 & \\
\hline & $93,85 \%$ & $6,15 \%$ & \\
\hline \multicolumn{4}{|l|}{ Place of living } \\
\hline \multirow{2}{*}{ City/town } & 60 & 17 & \multirow{4}{*}{$\begin{array}{c}\mathrm{Chi}^{2}=4,961 \\
\mathrm{p}=0,026\end{array}$} \\
\hline & $77,92 \%$ & $22,08 \%$ & \\
\hline \multirow{2}{*}{ Village } & 117 & 14 & \\
\hline & $89,31 \%$ & $10,69 \%$ & \\
\hline
\end{tabular}

\subsection{Health behaviours according to the HBI questionnaire}


Almost half of the patients (46,15\%) exhibited a high rate of health behaviours, whereas 40,39\% - an average rate, the remaining persons - a low rate, i.e. 13,46\%. The higher rate of health behaviours was exhibited more often by persons with more than 2 years after the disease diagnosis and by males over 65 years old, with higher education, living in a village (Table 4).

Table 4. Factors determining positive health behaviours (HBI).

\begin{tabular}{|c|c|c|c|c|c|c|c|c|c|c|c|}
\hline \multirow{2}{*}{$\begin{array}{l}\text { Variable } \\
\text { analyzed }\end{array}$} & \multicolumn{9}{|c|}{ Level of health behaviour indicator } & \multirow{2}{*}{\multicolumn{2}{|c|}{$\begin{array}{c}\mathrm{Chi}^{2} \\
\mathbf{p} \\
\end{array}$}} \\
\hline & \multicolumn{3}{|c|}{ low } & \multicolumn{3}{|c|}{ average } & \multicolumn{3}{|c|}{ high } & & \\
\hline \multicolumn{12}{|c|}{ Time after the disease diagnosis } \\
\hline 0-1 year & \multicolumn{3}{|c|}{$\begin{array}{c}17 \\
15,18 \%\end{array}$} & \multicolumn{3}{|c|}{$\begin{array}{c}52 \\
46,43 \%\end{array}$} & \multicolumn{3}{|c|}{$\begin{array}{c}43 \\
38,39 \%\end{array}$} & \multirow{2}{*}{\multicolumn{2}{|c|}{$\begin{array}{c}\text { Chi }^{2}=9,898 \\
p=0,041\end{array}$}} \\
\hline $1-2$ years & \multicolumn{3}{|c|}{$\begin{array}{c}6 \\
13,33 \%\end{array}$} & \multicolumn{3}{|c|}{$\begin{array}{c}19 \\
42,22 \%\end{array}$} & \multicolumn{3}{|c|}{$\begin{array}{c}20 \\
44,44 \%\end{array}$} & & \\
\hline Over 2 years & \multicolumn{3}{|c|}{$\begin{array}{c}5 \\
9,80 \% \\
\end{array}$} & \multicolumn{3}{|c|}{$\begin{array}{c}13 \\
25,49 \% \\
\end{array}$} & \multicolumn{3}{|c|}{$\begin{array}{c}33 \\
64,71 \% \\
\end{array}$} & & \\
\hline \multicolumn{12}{|l|}{ Sex } \\
\hline Males & \multicolumn{3}{|c|}{$\begin{array}{c}8 \\
8,33 \%\end{array}$} & \multicolumn{3}{|c|}{$\begin{array}{c}32 \\
33,33 \%\end{array}$} & \multicolumn{3}{|c|}{56} & \multirow{2}{*}{\multicolumn{2}{|c|}{$\begin{array}{c}C h i^{2}=11,408 \\
p=0,003\end{array}$}} \\
\hline Females & \multicolumn{3}{|c|}{$\begin{array}{c}20 \\
17,86 \%\end{array}$} & \multicolumn{3}{|c|}{$\begin{array}{c}52 \\
46,43 \%\end{array}$} & \multicolumn{3}{|c|}{$\begin{array}{c}58,33 \% \\
40 \\
35,71 \%\end{array}$} & & \\
\hline $\begin{array}{c}\text { Dependent } \\
\text { variable } \\
\text { analyzed } \\
\end{array}$ & \multicolumn{9}{|c|}{ Independent variable analyzed } & $\begin{array}{c}\text { Type of } \\
\text { test }\end{array}$ & $\mathbf{p}$ \\
\hline \multicolumn{12}{|l|}{ Age } \\
\hline & \multicolumn{3}{|c|}{ 1) up to 50 years } & \multicolumn{3}{|c|}{ 2) 51-65 years } & \multicolumn{3}{|c|}{ 3) over 65 years } & & \\
\hline & $\mathrm{M}$ & $\mathrm{Me}$ & SD & $\mathrm{M}$ & $\mathrm{Me}$ & $\mathrm{SD}$ & $\mathrm{M}$ & $\mathrm{Me}$ & $\mathrm{SD}$ & $\mathrm{H}$ & \\
\hline $\mathrm{HP}$ & 3,58 & 3,50 & 0,74 & 3,69 & 3,67 & 0,70 & 3,96 & 4,00 & 0,63 & 9,315 & 0,010 \\
\hline
\end{tabular}

Education

\begin{tabular}{lccc|ccc|cccccc}
\hline & \multicolumn{3}{c}{$\begin{array}{c}\text { 1) primary/ } \\
\text { vocational }\end{array}$} & \multicolumn{1}{c}{ 2) secondary } & \multicolumn{7}{c}{ 3) higher } \\
\cline { 2 - 10 } & $\mathrm{M}$ & $\mathrm{Me}$ & $\mathrm{SD}$ & $\mathrm{M}$ & $\mathrm{Me}$ & $\mathrm{SD}$ & $\mathrm{M}$ & $\mathrm{Me}$ & $\mathrm{SD}$ & $\mathrm{F} / \mathrm{H}$ & \\
\hline HBI sten & 5,89 & 6,00 & 1,89 & 6,64 & 7,00 & 1,62 & 6,63 & 6,00 & 1,81 & $6,922^{\mathrm{H}}$ & 0,031 \\
PH1 & 3,31 & 3,33 & 0,74 & 3,65 & 3,67 & 0,69 & 3,84 & 3,83 & 0,62 & $10,700^{\mathrm{F}}$ & $<0,001$ \\
\hline
\end{tabular}

Sex

\begin{tabular}{lccc|ccc|cc}
\hline & \multicolumn{7}{c}{ 1) Males } & \multicolumn{7}{c}{ 2) Females } & \\
\cline { 2 - 7 } & M & Me & SD & M & Me & SD & $\mathrm{t} / \mathrm{Z}$ & \\
HBI sten & 6,93 & 7,00 & 1,67 & 5,90 & 6,00 & 1,79 & $4,105^{z}$ & $<0,001$ \\
PH1 & 3,80 & 3,83 & 0,68 & 3,41 & 3,42 & 0,71 & $4,046^{\mathrm{t}}$ & $<0,001$ \\
\hline
\end{tabular}

Place of living

City/Town Village




\begin{tabular}{lccc|ccc|cc} 
& $\mathrm{M}$ & $\mathrm{Me}$ & $\mathrm{SD}$ & $\mathrm{M}$ & $\mathrm{Me}$ & $\mathrm{SD}$ & $\mathrm{Z}$ & \\
\cline { 2 - 8 } & 5,96 & 6,00 & 1,87 & 6,62 & 6,00 & 1,73 & $-2,188$ & 0,029 \\
HBI (sten) & 3,37 & 3,50 & 0,76 & 3,72 & 3,83 & 0,66 & $-3,078$ & 0,002 \\
\hline
\end{tabular}

M- mean; Me- median; SD- standard deviation; F - analysis of variance ANOVA; H- Kruskal-Wallis

$\mathrm{H}$ test;t- Student's t-test; Z- Mann - Whitney U test; $\mathrm{p}$ - significance level.

\subsection{Use of complementary and alternative medicine and health behaviours}

A statistically significant dependence was found between the health behaviour indicator and the use of complementary and alternative medicine $(p=0,001)$, the patients using CAM exhibited a higher level of health behaviours in comparison to the persons who did not use these methods. In case of the analysis of individual HBI categories, in relation to using or not using complementary and alternative medicine, significant statistical results were obtained for the health behaviour indicator (sten) $\mathrm{p}<0,001$, correct eating habits $\mathrm{p}<0,001$ and positive mental attitudes $\mathrm{p}=0,002$. Higher results were obtained by the patients using complementary and alternative medicine methods. (Table 5)

Table 5. Health behaviours according to HBI and the use of CAM.

\begin{tabular}{|c|c|c|c|c|c|c|c|c|}
\hline \multirow{2}{*}{$\begin{array}{l}\text { Level of health } \\
\text { behaviour indicator }\end{array}$} & \multicolumn{6}{|c|}{$\begin{array}{l}\text { Use of complementary and alternative medicine } \\
\text { methods }\end{array}$} & \multirow{2}{*}{\multicolumn{2}{|c|}{$\begin{array}{c}\mathrm{Chi}^{2} \\
\mathrm{p}\end{array}$}} \\
\hline & \multicolumn{3}{|c|}{ using } & \multicolumn{3}{|c|}{ not using } & & \\
\hline \multirow{2}{*}{ low } & \multicolumn{3}{|c|}{19} & \multicolumn{3}{|c|}{9} & \multirow{4}{*}{\multicolumn{2}{|c|}{$\begin{array}{c}\mathrm{Chi}^{2}=13,367 \\
\mathrm{p}=0,001\end{array}$}} \\
\hline & \multicolumn{3}{|c|}{$67,86 \%$} & \multicolumn{3}{|c|}{$32,14 \%$} & & \\
\hline \multirow{2}{*}{ average } & \multicolumn{3}{|c|}{68} & \multicolumn{3}{|c|}{16} & & \\
\hline & \multicolumn{3}{|c|}{$80,95 \%$} & \multicolumn{3}{|c|}{$19,05 \%$} & & \\
\hline \multirow{2}{*}{ high } & \multirow{2}{*}{\multicolumn{3}{|c|}{$\begin{array}{c}90 \\
93,75 \%\end{array}$}} & \multirow{2}{*}{\multicolumn{3}{|c|}{$\begin{array}{c}6 \\
6,25 \% \\
\end{array}$}} & & \\
\hline & & & & & & & & \\
\hline \multirow{3}{*}{ Variable analyzed } & \multicolumn{6}{|c|}{$\begin{array}{l}\text { Use of complementary and alternative medicine } \\
\text { methods }\end{array}$} & \multirow{3}{*}{$\mathrm{Z}$} & \multirow{3}{*}{$\mathrm{p}$} \\
\hline & \multicolumn{3}{|c|}{ using } & \multicolumn{3}{|c|}{ not using } & & \\
\hline & $\mathrm{M}$ & $\mathrm{Me}$ & SD & $\mathrm{M}$ & $\mathrm{Me}$ & SD & & \\
\hline HBI indicator (sten) & 6,59 & 7,00 & 1,74 & 5,16 & 5,00 & 1,68 & $\begin{array}{c}3,91 \\
7\end{array}$ & $<0,001$ \\
\hline $\begin{array}{l}\mathrm{CH} 1 \text {-Correct eating } \\
\text { habits }\end{array}$ & 3,70 & 3,83 & 0,67 & 2,97 & 3,00 & 0,67 & $\begin{array}{c}4,95 \\
9\end{array}$ & $<0,001$ \\
\hline $\begin{array}{l}\text { PB- preventive } \\
\text { behaviours }\end{array}$ & 3,67 & 3,67 & 0,67 & 3,46 & 3,33 & 0,64 & $\begin{array}{c}1,75 \\
8\end{array}$ & 0,079 \\
\hline $\begin{array}{l}\text { PA2- Positive mental } \\
\text { attitude }\end{array}$ & 3,84 & 3,83 & 0,65 & 3,45 & 3,33 & 0,65 & $\begin{array}{c}3,15 \\
8\end{array}$ & 0,002 \\
\hline HP- Health practices & 3,75 & 3,83 & 0,72 & 3,62 & 3,67 & 0,62 & $\begin{array}{c}0,90 \\
1\end{array}$ & 0,367 \\
\hline
\end{tabular}

M- mean; Me- median; SD- standard deviation; Z- Mann - Whitney U test; $\mathrm{p}$ - significance level.

\section{Discussion}

Contemporary clinical medicine has various methods of treating cancer at its disposal, nevertheless, numerous side effects are still common. In spite of using standard methods of cancer treatment, a great number of patients are looking for other alternative methods. An easy access to many sources of information encourages patients to gain knowledge on methods of complementary and alternative medicine and health behaviours. Analyzing the published studies conducted in Australia, Canada, Europe and the United States on the use of complementary and alternative medicine, Horneber et al. [2] noticed an increase in the use of CAM among patients with diagnosed cancer, from $25 \%$ in $1970-1980$ to $32 \%$ in the 90 s. and $49 \%$ after 2000 . In our own studies, most of the patients $(85,09 \%)$ declared that they use methods of complementary and alternative medicine. 
According to the studies conducted by Hierl at al. [12], Stan at al. [13], Nilsson at al. [14] and Teng at al. [15], the frequency of use ranged from $7,9 \%$ to 93,41 . Whereas the studies carried out among the Polish patients by Stanisz at al. [16], Augustyniuk et al. [17], Bielesz et al. [18], Woźniak-Holecka et al. [1] and Grabińska et al. [19], showed that the percentage of patients who declared using complementary and alternative medicine ranged from $16 \%$ to $55,5 \%$. The high variability in the percentage of people using complementary and alternative medicine methods is justified, at least partly, by the inconsistent definition of CAM, since some authors include only herbal medicines while others are also considering dietary supplements and alternative medical practices (massages, acupuncture).

In our own studies, out of numerous methods of complementary and alternative medicine, the patients most often choose to use natural products, as many as 95,48\% of persons using CAM, decided to choose natural products. Most often, the patients chose vitamin C, green tea, vitamin D and curcuma. Similar results were obtained in the studies carried out by Stanisz et al. [16], Stan et al. [13], Kwon et al. [20], Kessel et al. [21], Sárváryi et al. [22] and King et al. [23].

According to our own studies, a prayer constituted the highest percentage of body and mind practices - it was declared by $72,32 \%$ of the patients.

According to the studies conducted by Kang et al. [24], Demir et al. [25] and Amirmoezi et al. [26], a prayer is the most frequently used CAM method with respect to body and mind practices, regardless of the religion practised $(89,6 \%-92,2 \%)$.

Our own studies, aimed to determine the sociodemographic characteristics of oncological patients using CAM, showed that they were more often male residents of villages, with higher education, whereas age and marital status did not affect the use of complementary and alternative medicine by the respondents.

Higher education as a factor determining a higher percentage of patients using CAM was shown in the studies conducted by Jang et al. [27], Wode et al. [28], Bauml et al. [29], Nissen et al. [30], Garland et al. [31] and Hunter et al. [32].

According to the studies conducted by Stanisz et al. [16] and Wode et al. [28], the complementary and alternative medicine is more often used by younger patients, below the age 45 , while Bauml et al. [29], Garland et al. [31] and Ali-Shtayeh et al. [33] report that the age of 65 or below determined a higher frequency of using CAM [26, 28, 30].Sárváry et al. [22] report that residents of towns or cities use complementary medicine more often than the residents of villages( $89,8 \%$ and $76.5 \%$ respectively).

Gender is an essential determinant in making decisions about the use of CAM. In contrast to our own studies, those conducted by Hierl et al. [12], Wode et al. [28], Demir et al. [25], Dogu et al. [34], Garland et al. [31] and Stanisz et al. [16] prove that women decide to use CAM more often than men.

Studies carried out by Dhanoa et al. [35] related to the use of CAM show no impact of gender, marital status, education or employment status.

In our own studies, most of the patients reported highly effective (46\%), or slightly helpful effects of CAM. A high effectiveness of the therapies applied was also declared by the patients surveyed by Wode et al. [28] and Chang et al. [36]. According to the subjective opinions of the patients in our own studies, complementary medicine is effective in such areas as strengthening the immune system, helping to fight cancers and improving the quality and comfort of life. This hypothesis was confirmed by the studies conducted by Wode et al. [28]. In spite of using alternative medicine methods different from those used in the Western culture, the Saudi Arabian patients surveyed by Abuelgasim [37] reported similar positive effects: improving well-being and strengthening the immune system. A relatively high $(54 \%)$ percentage of adverse effects was reported by the Nigerian patients surveyed by Aliyu et al. [38]. Despite the fact that complementary and alternative medicine, according to the patients' subjective opinion, is usually helpful in the treatment of cancer, the studies carried out by Skyler et al [7] prove that the use of CAM doubled the risk of death in comparison to the patients who did not use alternative medicine.

In our own studies, the patients reported obtaining information on CAM from the Internet $(46,15 \%)$, from family members $(37,02 \%)$, from friends $(35,10 \%)$, from a doctor $(11,54 \%)$ and from a nurse $(5,77 \%)$. Similar results were obtained in the studies regarding the source of information on the use of CAM conducted by Buckner et al. [39], Lopez et al. [40], Bielesz et al. [18] and Hunter et al. 
[32]. Different results were obtained from German patients surveyed by Hierl et al. [12] - they show that doctors were most often mentioned $(29 \%)$ as a source of information about CAM, whereas family/friends constituted $24 \%$ of all answers , and the Internet - merely $11 \%$.

Our own studies showed that as many as $71,19 \%$ of the patients did not inform their oncologists about the use of complementary and alternative medicine. It proves the lack of communication between the healthcare staff and patients with diagnosed cancer as well as the fear that oncologists will not accept CAM. Stan et al [13] from the USA report that as many as $96 \%$ of the patients informed their oncologists about the use of complementary and alternative medicine. Similar results, i.e. 98\%, which concerned the American patients, were reported by McDermott [41]. According to the studies conducted by Berrett et al [42], in Italy, a slightly smaller percentage of patients (85\%) declared that they informed their oncologists about the use of CAM. Probably, cultural factors and the type of the health system play a role in the patients' willingness to disclose information about the use of complementary and alternative medicine to their physicians.

Our own studies also involved health behaviours of patients treated oncologically. The patients assessed with the Health Behaviour Inventory on the grounds of the sten scores usually obtained a high rate of health behaviours $(46,15 \%)$.

In the studies conducted by Bojakowska et al., 52,9\% of the female patients obtained high results, $30 \%$ - average and $17,1 \%$ - low results [43]. Our own studies showed that persons with higher education exhibited higher rate with respect to eating habits, whereas the studies carried out by Muszalik et al. in patients over the age of 60 with secondary and higher education demonstrated a higher rate with respect to healthy practices than those with primary and vocational education [44]. Our own studies demonstrated that a higher rate of health behaviours was most common in males over the age of 65, with higher education, living in a village.

The available Polish and English source literature do not provide any reports on studies related to the relationships between the use of complementary and alternative medicine and health behaviours of oncological patients. Our own studies demonstrated that patients using complementary and alternative medicine exhibited a higher rate of health behaviours than those who did not use these methods.

\section{Limitations of studies}

Our study is a cross-sectional one, therefore it does not show any cause-effect or time-effect relationships between CAM and the clinical condition of the patients. The study was conducted mainly in one Center in Poland, therefore it does not constitute a full representation for all oncological patients in the country. A relatively small sample and a small number of participants in the study may determine the preliminary results of the studies and it is worth continuing them on a larger number of cancer patients.

\section{Conclusions}

We observed that the majority of the surveyed patients suffering from cancer used complementary and alternative medicine and declared that it was very or slightly effective in strengthening the immune system and helpful in fighting cancer. We also demonstrated a relationship between health behaviours and the use of complementary and alternative medicine. The patients who used CAM exhibited a higher level of health behaviours than those who did not use these methods.

Due to the constantly growing interest of patients in complementary and alternative medicine, it is necessary to promote among patients educational activities in the field of CAM and to systematically recognize the use of unconventional treatment in patients at the stage of a standard medical interview. Taking into consideration patients' reluctance to disclose information on unconventional therapies to their doctors, healthcare staff, particularly including nurses, must be active in discussing CAM with patients and indicating a necessity to undergo conventional treatment. 
Authors' contribution: Supervision, writing, review and edition -BŚ; conceptualization, project administration, studies and research - ZSzSz, AJ, writing - original draft, AJ, ZSzSz- formal analysis; all authors read and agreed on the published version of the manuscript.

Acknowledgments: We would like to thank the Managers of the Oncology Centre for their support in the project implementation and all participants of this study for their generous cooperation.

Financing: These studies received no external financing.

Conflicts of Interest: The authors declare no conflict of interest.

\section{References}

1. Woźniak-Holecka, J.; Zborowska, K.;Holecki, T. Alternative medicine as a complementary form of treatment in the oncological patients' opinion. Psychooncology 2010;1, 21-28.

2. Horneber, M.; Bueschel, G.; Dennert, G.; Less, D.; Ritter, E.; Zwaglen, M. How many cancer patients use complementary and alternative medicine: a systematic review and metaanalysis. Integrative Cancer Therapies 2012,11, 187-203,doi: 10.1177/1534735411423920.

3. Bahall, M. Prevalence, patterns, and perceived value of complementary and alternative medicine among cancer patients: a cross-sectional, descriptive study. BMC Complementary and Alternative Medicine 2017,17, 1-9, dx.doi.org/10.1186\%2Fs12906-017-1853-6.

4. Edwards, G.V.;Aherne, N.J.; Horsley, P.;Benjamin,L.; McLachlan, C.; McKay, M.; Shakespeare, T. Prevalence of complementary and alternative therapy use by cancer patients undergoing radiation therapy. Asia-Pacific Journal of Clinical Oncology2014,10, 346-353, doi.org/10.1111/ajco.12203.

5. Keene, M.E; Heslop,I.M.; Sabesan,S.S.; Glass, B.D.; Complementary and alternative medicine use in cancer: A systematic review. Complementary Therapies in Clinical Practice 2016, 35, 33-47, doi.org/10.1016/j.ctcp.2019.01.004

6. Dulęba, K.; Wysocki, M.; Styczyński, J. Alternative and complementary therapy in children with cancer - facts and myths. Adv. Clin. Exp. Med. 2006,15, 695-703

7. Skyler, B.J.; Park, H.S.; Gross, C.P.; Yu, J.B. Complementary Medicine, Refusal of Conventional Cancer Therapy, and Survival Among Patients with Curable Cancers. JAMA Oncol. 2018, 4, 1375-1381, doi:10.1001/jamaoncol.2018.2487

8. Polska Liga Walki z Rakiem.Available online: https://www.ligawalkizrakiem.pl/rakniekonwencjonalnie (accesed on 17 July 2020).

9. Grosso, G.; Bella, F.;Godos, J.;Sciacca, S.; Del Rio, D.; Ray, S.; Galvano, F.; Giovannucci, E.L. Possible role of diet in cancer: systematic review and multiple meta-analyses of dietary patterns, lifestyle factors, and cancer risk. Nutrition Reviews 2017, 75, 405-419, doi.org/10.1093/nutrit/nux012.

10. Hamer, J.; Warner, E. Lifestyle modifications for patients with breast cancer to improve prognosis and optimize overall health. CMAJ 2017, 189, 268-274, dx.doi.org/10.1503\%2Fcmaj.160464.

11. Juczyński Z. Measurement tools in health promotion and health psychology. Psychological Test Lab of the Polish Psychological Association: Warszawa, 2001, Part C: Health behaviors and health valuation, 110116, ISBN 978-83-60733-43-1.

12. Hierl, M.;Pfirstinger, J.; Andreesen, R.;Holller, E.; Mayer, S.; Wolff, D.; Vogelhuber, M. Complementary and Alternative Medicine: A Clinical Study in 1,016 Hematology/Oncology Patients. Oncology 2017,93, 157-163,doi.org/10.1159/000464248.saw 
13. Stan, D.L.;Wahner-Roedler, D.L.; Yost, K.J.; O’Byrne, T.J.; Branda, M.E.; Leppin, A.;Tilburt, J.C. Absent and Discordant Electronic Health Record Documentation of Complementary and Alternative Medicine in Cancer Care. The Journal of Alternative and Complementary Medicine 2018,24, 988-995, doi.org/10.1089/acm.2018.0141.

14. Nilsson, J.;Källman, M.;Östlund, U.;Holgersson, G.; Bergqvist, M.;Bergström, S. The Use of Complementary and Alternative Medicine in Scandinavia. Anticancer Research 2016,7, 3243-3251.

15. Teng, L.;Jin, K.; He, K.;Bian, C.; Chen, W.; Fu, K.; Zhu, T.;Jin, Z. Use of complementary and alternative medicine by cancer patients at Zhejiang University Teaching Hospital Zhuji Hospital, China. African Journal of Traditional, Complementary and Alternative Medicine 2010, 7, 322-330, doi.org/10.4314/ajtcam.v7i4.56699.

16. Stanisz, M.; Wojciechowska, A.; Branecka-Woźniak, D.; Kurzawa, R.; Ciepiela, P.; Wróbel, A. Complementary and alternative methods as therapies used by patients during systemic treatment of cancer. Polish Nursing 2019, 71, 42-47.

17. Augustyniuk, K.; Brudnoch, K.;Owsianowska, J.; Schneider-Matyka, D.; Jurczak, A.;Karakiewicz, B. Use of alternative and complementary methods by patients with diagnosed cancer undergoing chemotherapy. Fam Med. Prim. CareRev. 2016,18, 7-11, doi.org/10.5114/fmpcr/42566.

18. Bielesz, K.; Plutowski, D.; Sokołowski, F.;Strzelczyk, W.; Kieszkowska-Grudny, A.; Rucińska, M. Searching of knowledge about own disease and using alternative therapy methods among patients undergoing radiotherapy, Psychooncology 2015,2, 43-48.

19. Grabińska, K.; Szewczyk-Cisek, I.;Hernik, P.;Mykała-Cieśla, J.;Kaziród, D. Psychosocial problems and needs of patients undergoing oncological chemotherapy. Psychooncology 2011,2, 39-47.

20. Kwon, J.H.; Lee, S.C.; Lee, M.A.; Kim, Y.J.; Kang, J.H.; Kim, J.Y.; Lee, H.J.; Bae, W.K.; Kim, M.J.; Chie, E.K.; et al.Behaviors and Attitudes toward the Use of Complementary and Alternative Medicine among Korean Cancer Patients. Cancer Re: Treat. 2019,51, 851-860,doi:10.4143/crt.2019.137.

21. Kessel, K.A.;Lettner, S.; Kessel, C.; Bier, H.; Biedermann, T.; Friess, H.; Herrschbach, P.; Gschwend, J.E.; Meyer, B.; Peschel, C.; et al. Use of Complementary and Alternative Medicine (CAM) as Part of the Oncological Treatment: Survey about Patients' Attitude towards CAM in a University-Based Oncology Center in Germany. PLoS ONE 2016, 11, 1-13, doi.org/10.1371/journal.pone.0165801.

22. Sárváry, A.; Sárváry, A. Use of complementary and alternative medicine among breast cancer patients in Hungary: A descriptive study. Complementary Therapies in Clinical Practice 2019, 35, 195-200, doi.org/10.1016/j.ctcp.2019.02.013.

23. King, N.;Balneaves, L.B.; Levin, G.T.; Nguyen, T.; Nation, J.G.; Card, C.; Truant, T.; Carlson L.E. Surveys of Cancer Patients and Cancer Health Care Providers Regarding Complementary Therapy Use, Communication, and Information Needs. Integrative Cancer Therapies 2015, 14, 515-524, doi.org/10.1177/1534735415589984.

24. Kang, D.H.; McArdle, T.; Suh, T. Changes in Complementary and Alternative Medicine Use Across Cancer Treatment and Relationship to Stress, Mood, and Quality of Life. The Journal of Alternative and Complementary Medicine 2014, 11, 853-859, dx.doi.org/10.1089\%2Facm.2014.0216.

25. Demir, B.D.; Erol, O. Complementary and Alternative Medicine Use among Turkish Cancer Patients and the Influencing Factors. International Journal of Caring Sciences 2018, 11, 319-332.

26. Amirmoezi, F.;Araghizadeh, M.;Mohebbinia, Z.; Kamifiroozi, R.; Haghpanah S.; Bordbar, M. Use of Complementary and Alternative Medicine Among Iranian Cancer Patients in South of Iran. International Journal of Cancer Management 2017,10, 1-7, dx.doi.org/10.5812/ijcm.7233. 
27. Jang, A.; Kang, D.H.; Kim, D.U. Complementary and Alternative Medicine Use and Its Association with Emotional Status and Quality of Life in Patients with a Solid Tumor: A Cross-Sectional Study. Journal of alternative and complementary medicine 2017, 23, 362-369, doi.org/10.1089/acm.2016.0289.

28. Wode, K..;Henriksson, R.; Sharp, L.; Stoltenbert, A.; Nordberg, J.H. Cancer patients' use of complementary and alternative in Sweden: a cross-sectional study. BMC Complementary and Alternative Medicine 2019,62, 1-11, doi.org/10.1186/s12906-019-2452-5.

29. Bauml, J.;Chokshi, M.; Shapira, M.; Im, E.; Li, S.; Langer, C.; Ibrahim, S.; Mao, J. Do Attitudes and Beliefs About Complementary and Alternative Medicine Impact Utilization Among Patients with Cancer? A Cross-Sectional Survey. Cancer2015,121, 2431-2438, dx.doi.org/10.1002\%2Fcncr.29173.

30. Nissen, N.; Lunde, A; Pedersen, C.; Johannessen, H. The use of complementary and alternative medicine after the completion of hospital treatment for colorectal cancer: findings from a questionnaire study in Denmark. BMC Complementary and Alternative Medicine 2014, 14, 1-8, dx.doi.org/10.1186\%2F1472-6882-14-388.

31. Garland, N.; Valentine, D.; Desai, K.; Li, S.; Langer, C.; Evans, T.; Mao, J. Complementary and Alternative Medicine Use and Benefit Finding Among Cancer Patients. The Journal of Complementary and Alternative Medicine 2013; 19, 876-881, doi.org/10.1089/acm.2012.0964.

32. Hunter, D.; Oates, R. Complementary and alternative medicine use and disclosure amongst Australian radiotherapy patients. Supportive care in cancer 2014, 22, 1571-1578, doi.org/10.1007/s00520-014-2120-8

33. Ali-Shtayeh, M.jJamous, R.M.; Salameh, N.; Jamous, R.M.; Hamadeh, A. Complementary and alternative medicine use among cancer patients in Palestine with special reference to safety - related concerns. Journal of Ethnopharmacology 2016, 187, 104-122, doi.org/10.1016/j.jep.2016.04.038.

34. Dogu, G.G.;Kargi, A.;Tanriverdi, O.; Yaren, A.; Demiray, G.; Taskoylu, B.Y.; Ergin, A. Complementary/Alternative Medicine Experience in Cancer Patients: A Questionnaire-Based Survey. International Journal of Hematology and Oncology 2014, 24, 45-52, doi: 10.4999/uhod.12008.

35. Dhanoa, A.; Yong, T.Z.; Yeap, S.; Lee, I.; Singh, V. Complementary and alternative medicine use amongst Malaysian orthopaedic oncology patients. BMC Complementary and Alternative Medicine 2014, 14, 1-11, doi.org/10.1186/1472-6882-14-404.

36. Chang, K.H.; Brodie, R.; Choong, M.A.; Sweeney, K.J.; Kerin, M.J. Complementary and alternative medicine use in oncology: A questionnaire survey of patients and health care professionals. BMC Cancer 2011, 11, 1-9, doi.org/10.1186/1471-2407-11-196.

37. Abuelgasim, K.A.;Alsharhan, Y.;Alenzi, T.; Alhazzani, A.; Ali, Y.Z.; Jazieh, A.R. The use of complementary and alternative medicine by patients with cancer: a cross-sectional survey in Saudi Arabia. BMC Complementary and Alternative Medicine 2018, 18, 1-8, doi.org/10.1186/s12906-018-2150-8.

38. Aliyu, U.M.; Awosan, K.J.; Oche, M.O.; Jimoh, A.O.; Okuofo, E.C. Prevalence and Correlates of Complementary and Alternative Medicine Use among Cancer Patients in usmanu danfodiyo University Teaching Hospital, Sokoto, Nigeria. Nigerian Journal of Clinical Practice 2018,20, 1576-1583, DOI: $10.4103 /$ njcp.njcp_88_17.

39. Buckner, C.A.; Lafrenie, R.M.; Dénommée, J.A.; Caswell, J.M.; Want, D.A. Complementary and alternative medicine use in patients before and after a cancer diagnosis. Current Oncology2018,25, 275281, doi.org/10.3747/co.25.3884.

40. Lopez, G.; Salas, C.A.; Cadiz, F.; Cadiz, F.; Barriga, C., Gonzalez, P.; Acevedo, S.; Raimilla, P.; Pincheira, P.; Naing, A.; Quiroga, M. Complementary and Integrative Medicine Use in Individuals Seeking 
Conventional Medical Oncology Care in Chile: Prevalence and Patient Characteristics. Journal of Global Oncology 2019,5, 1-5, doi.org/10.1200/jgo.18.00190.

41. McDermott, C.L.; Blough, D.K.;Fodorenko, C.R.; Arora, N.K.; Zeliadt, S.B.; Fairweather, M.E.; OakleyGirvan, I.; Van Den Eeden, S.K.; Ramsey, S.D. Complementary and alternative medicine among newly diagnosed prostate cancer patients. Support Care Cancer 2012, 20, 65-73, doi.org/10.1007/s00520-0101055-y.

42. Berretta, M.;Pepa, C.D.;Tralongo, P.; Fulvi, A.; Martellotta, F.; Lieshi, A.; Nasti, G.; Fisichella, R.; Romano, C.; De Divitiis C. Use of Complementary and Alternative Medicine (CAM) in cancer patients: An Italian multicenter survey, Oncotarget 2017,8, 24401-24414, doi.org/10.18632/oncotarget.14224.

43. Bojakowska, U.J.; Kalinowski, P.; Kowalska, M.E. Assessment of selected health behaviours before and after the diagnosis of the disease among women with breast cancer, based on Juczyński'sthe Health Behaviour Inventory - preliminary study.Journal of Education, Health and Sport 2016; 6, 29-37, dx.doi.org/10.5281/zenodo.50958.

44. Muszalik, M.; Zielińska-Więczkowska, H.; Kędziora - Kornatowska, K.; Kornatowski, T. Assessment of selected health-promoting behaviours among the elderly based on Juczyński'sthe Health Behaviour Inventory in terms of socio-demographic factors. Hygiene and Epidemiology Problems 2013,94, 509-513. 